\title{
Durability Performance of Binary and Ternary Blend Self Compacting Concrete using Waste Marble Powder and Lime Powder
}

\author{
Panchal Vinod. C, Vesmawala G.R
}

\begin{abstract}
Investigation practicing waste marble powder and lime powder as cement supplements in Self-compacting concrete (SCC) has obtained positive outcomes newly. In this research, waste marble powder $(M W)$ and waste lime powder $(L W)$ with the different combinations used in the design of SCC by replacement of cement $0,10,15$ and $20 \%$. In addition, $5 \% \mathrm{H}_{2} \mathrm{SO}_{4}$ and $5 \%$ $\mathrm{MgSO}_{4}$ practiced for durability study and evaluate the effect of Sulfate attack and acid attack on filler content of mix after 28,56, and 90 days curing of SCC sample. The results of the visual assessment and weight loss revealed that the increase in the amount of $L W$ would enhance the performance of concrete, while the inclusion of $L W$ and $M W$ in SCC has shown positive results in terms of resistance against acid and sulfate attack. The mixtures with ternary binders of $O P C, M W$, and $L W$ experienced the lowest strength loss after exposure to high concentrations of sulfate attack compared to unblended SCC.
\end{abstract}

Keywords: Limestone powder waste (LW), Marble powder waste (MW), Sulfate resistance, Acid attack.

\section{INTRODUCTION}

$E_{\text {conomy, durability, and sustainability are a principal }}$ parameter in today's construction industry. In recent years many quite important studies about self-compacting concrete (SCC) executed. The most important dissimilarity between SCC and regular concrete is the existence of filler material, low water powder ratio, and plasticizers in the SCC mixture[1]. The natural ingredient of concrete is limited and becomes costly day by day and could be solved to minimize waste and by using waste produced during the extraction of natural materials [2].

The powder waste of marble and lime is step by step increasing in India. Additionally, the dumping at the remote site, hilly, and town area is costly, as well as creates numerous challenges in the environment. Hence, to utilize these wastes as filler in the cement-based product is of prime importance for sustainability issues. Use of various waste materials in SCC, like marble powder and lime powder, contribute to the saving of natural resources for sustainable

Revised Manuscript Received on February 05, 2020.

* Correspondence Author

Panchal Vinod.C, *,Applied mechanics Department, Research Scholar, SVNIT , Surat (Gujarat)-India, vinodpanchal11@yahoo.com

Vesmawala G.R, Applied mechanics Department, Associate professor, SVNIT, Surat (Gujarat)-India, grv22@yahoo.com

(C) The Authors. Published by Blue Eyes Intelligence Engineering and Sciences Publication (BEIESP). This is an open access article under the CC BY-NC-ND license (http://creativecommons.org/licenses/by-nc-nd/4.0/) development and render economic advantages. Hence it can be stated that the Limestone powder and marble powder provide two-way benefits in terms of filler as cost-effectiveness and as a by-product of SCC to protect the environment [3-5].

The durability of a concrete structure depends on the number of parameters; crack is one of them, which form during the initial setting time after laying and compaction of concrete. The hot climatic condition and the high evaporation losses cause surface cracks. Through this passage of a crack, the harmful agent (gases and solution) penetrate in structure and start to degrade the framework of concrete [6]. Assi et al.[1], comparing the vibrated concrete to different mixes of SCC for durability indicator and revealed that using similar raw materials and equal level of compressive strength, the durability of SCC was more reliable.

P. Dinakar et al.[7] studied, the durability properties, the outcomes showed higher water absorption and higher voids in SCC than the reference mix. Though, the SCC had a low mass loss in acid attack test. This research work defines the principal properties that produce green concrete self-compacting and durable. This work presents a systematic experimental program on durability studies carried, comprising M30 grad of SCC with a different combination of filler. The durability studies cover sulfate attack, acid attack, and weight loss test.

The main intention of this research is to produce SCC mixes that are resistant to sulfate attack suitable for Indian temperature conditions compared with usual concrete. The $5 \%$ concentrations of $\mathrm{MgSO}_{4}$ and $\mathrm{H}_{2} \mathrm{SO}_{4}$ solution employed to examine the resistance of concrete specimens for a total exposure period of ninety days. The performance of the degraded specimens was evaluated by measuring the weight loss, change in strength and visual assessment.

\section{MTERIALS AND METHODS}

The durability examination proposes to assess the different blends of fills content as binary and ternary mixes of SCC to obtain better workability with long term strength. Ordinary Portland Cement 53 grade for design mix of SCC practiced, which satisfy the Indian standard [8] and ASTM C150[9] specification used in existing experimental work. A modified Nan Su method [10,11] used to design SCC mixes. Natural crushed granite aggregate of $16 \mathrm{~mm}$ maximum size and clean, dry siliceous sand of specific gravity and fineness modulus $2.71,2.67$, and $2.79,2.63$, respectively conform to IS 383 [12]. 
The content of the coarse and fine aggregate kept constant $794.0 \mathrm{~kg} / \mathrm{m}^{3}$ and $997.0 \mathrm{Kg} / \mathrm{m}^{3}$ respectively, for all unblended and blended SCC mixes. Wire basket method employed to obtain the specific gravity of coarse aggregate following the ASTM C-127 [13]. The potable water of the temperature of $28 \pm 10 \mathrm{C}^{0}$ and natural waste fillers LW and MW passing from $125 \mu \mathrm{m}$ sieve used for the all samples.

The Superplasticiser (1.0\%) weight of powder content naphthalene formaldehyde-based exercised to lessen water demand in SCC. To reduce bleeding and segregation in the mix, Viscosity Modifying Agent (VMA) 0.20\% employed. Separate trials conducted in developing SCC mixes to satisfy the EFNARC guideline [14]. Five different combinations of fillers for each replacement $0 \mathrm{LW}-100 \mathrm{MW}, 25 \mathrm{LPW}-75 \mathrm{MW}$, 50LW-50MW, 5LW-25MW and 100LW-0MW prepared; for example, the mix $25 \mathrm{LW}-75 \mathrm{MW}$ stands for $25 \%$ limestone powder waste and $75 \%$ marble powder waste used in 10, 15 and 20\% oppose to cement. Total fifteen SCC mixes with different replacement levels $0,10,15$, and $20 \%$ prepared and cast. Among all, one mix of without filler (SCC0) cast. Since Acid and Sulfate attack is a principal factor produces complications in concrete, leading to critical damages such as the development of micro cracks, its expansion, and degeneration of concrete member [15]. Table 1 displays the chemical proportion of LW and MW filler. Five percent (5\%) $\mathrm{H}_{2} \mathrm{SO}_{4}$ and sulfate $\mathrm{MgSO}_{4}$ used in this work to observe the deterioration of concrete when cured in it. Additionally, compressive strength, and weight loss tests performed on the
SCC samples and compared with reference mix of SCC Table II represents different designed mix of SCC and SCC0.

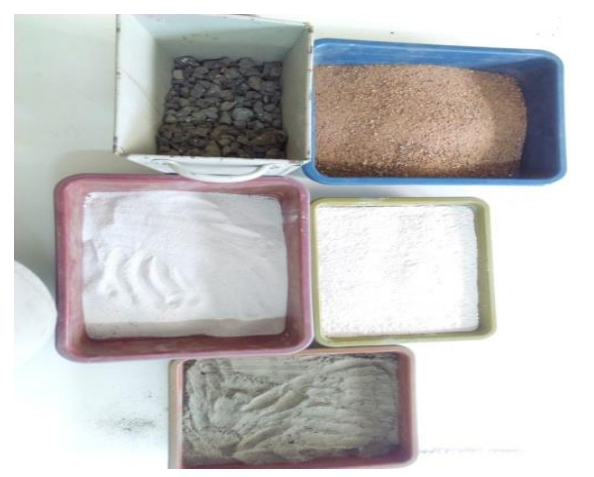

Fig. 1 SCC ingredients for Design mix M30

Table I Chemical proportion of LW and MW filler

\begin{tabular}{|l|c|c|}
\hline Composition & LW (\%) & MW (\%) \\
\hline $\mathrm{SiO}_{2}$ & 4.23 & 1.16 \\
\hline $\mathrm{CaO}$ & 95.61 & 89.16 \\
\hline $\mathrm{Al}_{2} \mathrm{O}_{3}$ & 0.87 & 0.82 \\
\hline $\mathrm{Fe}_{2} \mathrm{O}_{3}$ & 0.46 & 0.05 \\
\hline $\mathrm{SO}_{3}$ & 1.34 & 0.63 \\
\hline Specific gravity & 2.4 & 2.5 \\
\hline Loss on ignition & 1.26 & 2.18 \\
\hline
\end{tabular}

Table. II Mix proportion of SCC for M30 $\left(\mathrm{kg} / \mathrm{m}^{3}\right)$ with filler materials

\begin{tabular}{|c|c|c|c|c|c|c|}
\hline $\begin{array}{l}\text { Mix } \\
\text { Type }\end{array}$ & $\begin{array}{c}\text { Cement } \\
(\mathrm{kg})\end{array}$ & $\begin{array}{c}\text { Water } \\
\left(\mathrm{Kg} / \mathrm{m}^{3}\right)\end{array}$ & $\begin{array}{c}\text { Lime Powder } \\
\text { waste (K/g) }\end{array}$ & $\begin{array}{c}\text { Marble powder } \\
\text { waste.(K/g) }\end{array}$ & \% Replace & $\begin{array}{c}\text { Cube } \\
\text { compressive } \\
\text { strength } \\
\end{array}$ \\
\hline SCC0 & 404 & 173.7 & 0 & 0 & 0 & 34.74 \\
\hline $\mathrm{A}$ & 363.6 & 168.5 & 0 & 40.4 & 10 & 39.3 \\
\hline B & 363.6 & 168.5 & 10.1 & 30.3 & 10 & 36.45 \\
\hline $\mathrm{C}$ & 363.6 & 168.5 & 20.2 & 20.2 & 10 & 36.3 \\
\hline $\mathrm{D}$ & 363.6 & 168.5 & 30.3 & 10.1 & 10 & 36.1 \\
\hline $\mathrm{E}$ & 363.6 & 168.5 & 40.4 & 0 & 10 & 35.9 \\
\hline $\mathrm{F}$ & 343.4 & 167.2 & 0 & 60.6 & 15 & 42.15 \\
\hline G & 343.4 & 167.2 & 15.15 & 45.45 & 15 & 41.7 \\
\hline $\mathrm{H}$ & 343.4 & 167.2 & 30.3 & 30.3 & 15 & 39.26 \\
\hline I & 343.4 & 167.2 & 45.45 & 15.15 & 15 & 34.15 \\
\hline $\mathrm{J}$ & 343.4 & 167.2 & 60.6 & 0 & 15 & 34.55 \\
\hline K & 323.2 & 166.3 & 0 & 80.8 & 20 & 36.9 \\
\hline $\mathrm{L}$ & 323.2 & 166.3 & 20.2 & 60.6 & 20 & 36.15 \\
\hline $\mathrm{M}$ & 323.2 & 166.3 & 40.4 & 40.4 & 20 & 34.45 \\
\hline $\mathrm{N}$ & 323.2 & 166.3 & 60.6 & 20.2 & 20 & 33.9 \\
\hline $\mathrm{O}$ & 323.2 & 166.3 & 80.8 & 0 & 20 & 32.5 \\
\hline $\begin{array}{l}{ }^{\text {А }} 0 L W-100 \\
\text { F } 0 L W-100 \\
\text { к } 0 L W-100\end{array}$ & $\begin{array}{l}\text { в } 25 \mathrm{~L} \\
\text { s } 25 \mathrm{LI} \\
\mathrm{L} 25 \mathrm{LI}\end{array}$ & $\begin{array}{l}\%),{ }^{\mathrm{C}} 5 \\
\%),{ }^{\mathrm{H}} 50 \\
\%)^{\mathrm{M}} 5(\end{array}$ & $\begin{array}{l}\text { IW(10\%), } \\
\text { W(15\%), } \\
\text { W(20\%), } \\
\text { N7 }\end{array}$ & $\begin{array}{l}\text { V-25MW(10\%) } \\
-25 M W(15 \%), \\
\text { V-25MW(20\%) }\end{array}$ & $\begin{array}{l}\text { OLW-0MW( } \\
\text { LW-0MW(15 } \\
\text { OLW-0MW( }\end{array}$ & \\
\hline
\end{tabular}

\section{TEST RESULTS AND DISCUSSION}

Since the workability is directly proportional to the strength of concrete in SCC, the workability performance test performed and mix has satisfied the workability criteria of EFNARC guideline [14]. The workability of concrete at a plastic state is a prerequisite to obtained adequate strength of concrete at a hardened state. Hence, the SCC cannot be put and packed well [16].

\section{A. Acid attack test of SCC and SCCO}

For evaluating the resistance of SCC mixtures to the aggression of sulfuric acid, there are no such standards in the ASTM which solely devoted. Therefore, ASTM C267 [17] is the approved test method for the chemical resistance of the grouts, mortars, and polymer concrete used as the source for acid attack test method. 
The specimens of SCC, after twenty-eight days of wet curing, dipped in a sulfuric acid of $5 \%$ concentration. To examining the resistance of SCC specimens, the specimens kept for a total exposure period of ninety days.

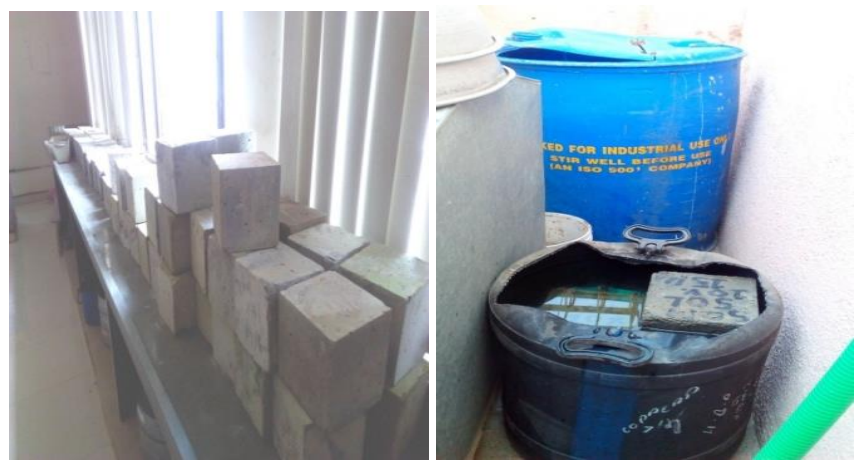

Fig. 2 Acid and sulfate attack test specimen arrangement

The containers had a capacity of around 180 liters utilized to prepare the acidic solutions. The test samples kept in two courses with every course consisting of 3 samples inside the barrels. The submerged time of the specimen separated into three rounds or phases. The length of each round was four weeks. Accordingly, the total length of the testing was 12 weeks as shown in Fig.2. The $\mathrm{pH}$ of the solutions observed and agitated once in a week to produce a uniform effect of solution around the immersed specimens. The $150 \mathrm{~mm}$ cubes examined for compressive strength by ensuring the method directed in IS 516 [18]. This type of accelerated experiment of obtaining the loss of compressive strength for evaluating the sulfate resistance of concrete conducted by [19].The initial weight and the average compressive strength of three concrete samples of all the specimens measured and recorded as per ASTM C267[17] before the immersion. The functioning of the degraded specimen estimated by evaluating the decline of mass, vary in strength, and visible assessment. Fig.2 implies that the SCC blended sample and SCC0 acted more or less related percentage decline in strength for the equivalent grade of concrete. Owing to an acidic situation, the interference in the geometry of the specimens of SCC mixes and SCC0 mix have observed and measured the loss of mass.

From the visible assessment as shown in Fig. 2\&3 it interpreted that up to $60.0 \mathrm{~kg} / \mathrm{m}^{3}(15 \%)$ replacements, the diagonal dimensional loss was less affected within the case of SCC filler samples, and more crucial loss within the SCC0 sample. Furthermore, on the surface of specimen brown yellow spots observed with loose powder paste and the corners of the SCC0 cube specimen converted from a cutting edge to round due to the influence of an acid attack. The rate of mass loss shown in Fig 2 after immersion in $5 \% \mathrm{H}_{2} \mathrm{SO}_{4}$ solution at 28, 56 and 90 days, gained to be lower from $4.73 \%$ to $12 \%, 4.44 \%$ to $8.11 \%$ and $8.41 \%$ to $14.10 \%$ for 10,15 and $20 \%$ replacement respectively, for all blended SCC samples. While the higher loss of mass noted in SCC0 started from $13.3,18.4$, and $23.4 \%$ for 28,56 , and 90 days respectively, compared to its initial weight. A comparison for all the SCC samples and SCC0 revealed that SCC specimens performed better and offered more resistance against the chemical reaction of acidic solution than SCC0 specimens.

When compared, out of the three percentage replacement, the $15 \%$ filler opposed to the cement of five blended samples has resulted in less loss of weight than the other two. Also, loss of weight during the time span from 28 to 90 days was less in the case of $15 \%$ samples. The acid strength loss factor and acid durability factor evaluated by Rao V.S [20] concluded that the performance-based design is relevant instead of the strength-based design of the concrete.

The loss of compressive strength after 28, 56 and 90 presented in Fig.3 for all blended and SCC0 mixes. The decline of compressive strength after 28.56 and 90 days in the acidic solution presented in Table III and Fig.4 for all blended and SCC0 mixes. The loss of compressive strength for SCC0 specimen for three acidic immersion period after ninety days obtained nearer to $53 \%$ higher compared to 28 days water curing strength. The same period up to ninety days of curing in $\mathrm{H} 2 \mathrm{so} 4$ solution for all blended mixes gave about $7 \%$ in $10 \%$ and 5 to $6 \%$ in most of the mixes of $15 \%$ replacement. While for $20 \%$ replacement resulted in up to $29 \%$ decline value excluding one sample of same group $0 \mathrm{LW}-100 \mathrm{MW}$ unexpected loss value of $7 \%$. Hence, the binary and ternary blends in this study up to $15 \%$ replacement offer higher resistance against acidic condition than that in different less or higher percentage combined binder.

The destruction is reflected to be a progressive corporal attack or physical sulfate attack [21]. In this process, ettringite formed when Calcium sulfate reacts with $\mathrm{C}_{3} \mathrm{~A}$ content [22]. This results in weaken the bond of Calcium silicate hydrates of paste to aggregate and causes serious rearrangement of its physiological microstructure.

\section{B. Sulfate attack test for SCC and SCCO}

Sulfate attack is one of the common critical problems concern with the strength and stability of all types of concrete structures. The paste of concrete experiences deterioration resulting in the development of micro cracks, spalling and diminishing under the sulfate conditions [21].

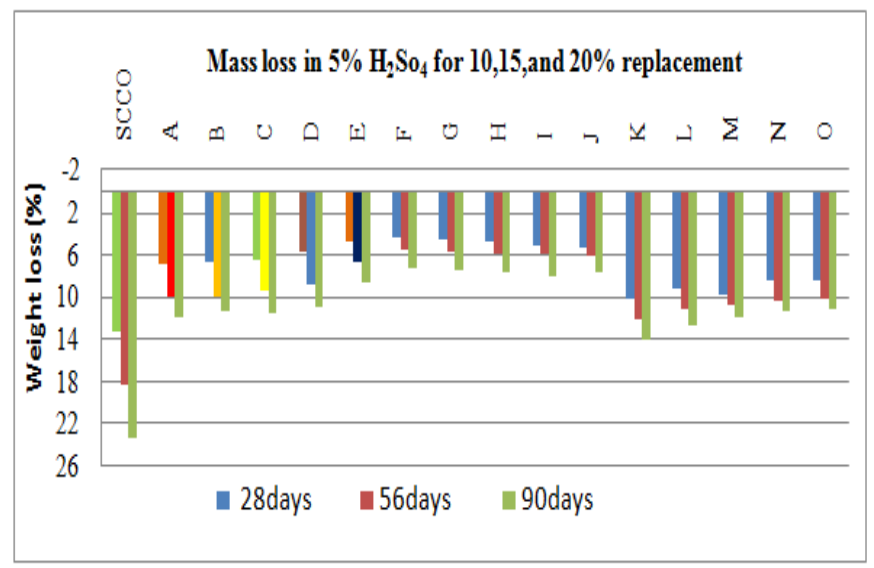

Fig.3 Acid attack weight loss test results for $10 \%, 15 \%$ and $20 \%$ replacement 
Durability Performance of Binary and Ternary Blend Self Compacting Concrete using Waste Marble Powder and Lime Powder

Table III Strength after curing of SCC samples in Water, $\mathrm{H}_{2} \mathrm{SO}_{4}$ and $\mathrm{MgSO}_{4}$ solution for 28, 56 and 90 days.

\begin{tabular}{|c|c|c|c|c|c|c|c|c|}
\hline Mix type & $\begin{array}{c}\mathbf{2 8} \text { Days } \\
\text { water } \\
\text { curing }\end{array}$ & $\begin{array}{c}\mathbf{2 8} \text { Days in } \\
\mathbf{H}_{\mathbf{2}} \mathbf{S O}_{\mathbf{4}}\end{array}$ & $\begin{array}{c}\mathbf{5 6} \text { Days in } \\
\mathbf{H}_{\mathbf{2}} \mathbf{S O}_{\mathbf{4}}\end{array}$ & $\begin{array}{c}\mathbf{9 0} \text { Days in } \\
\mathbf{H}_{\mathbf{2} \mathbf{S O}_{\mathbf{4}}}\end{array}$ & $\begin{array}{c}\mathbf{2 8} \text { Days in } \\
\mathbf{M g S O}_{\mathbf{4}}\end{array}$ & $\begin{array}{c}\mathbf{5 6} \text { Days in } \\
\mathbf{M g S O}_{\mathbf{4}}\end{array}$ & $\begin{array}{c}\mathbf{9 0} \text { Days in } \\
\mathbf{M g S O}_{\mathbf{4}}\end{array}$ & $\begin{array}{c}\text { UPV } \\
\text { values } \\
\mathbf{( K m} / \mathbf{s})\end{array}$ \\
\hline SCC0 & 34.74 & 30.33 & 26.43 & 16.21 & 32.04 & 30.28 & 29.3 & 4.42 \\
\hline A & 39.3 & 37.85 & 37.75 & 36.27 & 38.67 & 37.92 & 37.12 & 4.68 \\
\hline B & 36.45 & 36.11 & 35.43 & 34.1 & 34.86 & 34.24 & 33.89 & 4.56 \\
\hline C & 36.3 & 35.51 & 35.25 & 34.47 & 35.5 & 34.05 & 33.97 & 4.34 \\
\hline D & 36.1 & 35.21 & 34.57 & 34.14 & 34.84 & 34.45 & 33.6 & 4.38 \\
\hline E & 35.9 & 34.8 & 34.08 & 33.78 & 35.45 & 35.15 & 34.18 & 4.12 \\
\hline F & 42.15 & 41.12 & 39.31 & 38.85 & 40.43 & 39.78 & 39.43 & 5.31 \\
\hline G & 41.7 & 38.24 & 37.81 & 38.11 & 39.67 & 39.56 & 39.21 & 4.97 \\
\hline H & 39.26 & 37.9 & 37.78 & 37.08 & 38.9 & 38.21 & 37.33 & 4.61 \\
\hline I & 34.15 & 33.12 & 32.89 & 32.56 & 33.81 & 33.45 & 32.8 & 3.51 \\
\hline J & 34.55 & 34.1 & 33.64 & 33.1 & 34.1 & 33.64 & 33.1 & 3.67 \\
\hline K & 36.9 & 34.21 & 34.43 & 34.16 & 36.11 & 34.55 & 34 & 4.15 \\
\hline L & 36.15 & 33.13 & 31.21 & 30.17 & 35.24 & 34.32 & 33 & 4.17 \\
\hline M & 34.45 & 31.21 & 28.23 & 27.43 & 33.1 & 32.45 & 31.67 & 2.87 \\
\hline N & 33.9 & 30.21 & 26.16 & 25.31 & 32.78 & 32.31 & 30.42 & 2.56 \\
\hline O & 32.5 & 27.15 & 25.33 & 22.97 & 31.45 & 30.8 & 28.56 & 2.71 \\
\hline
\end{tabular}

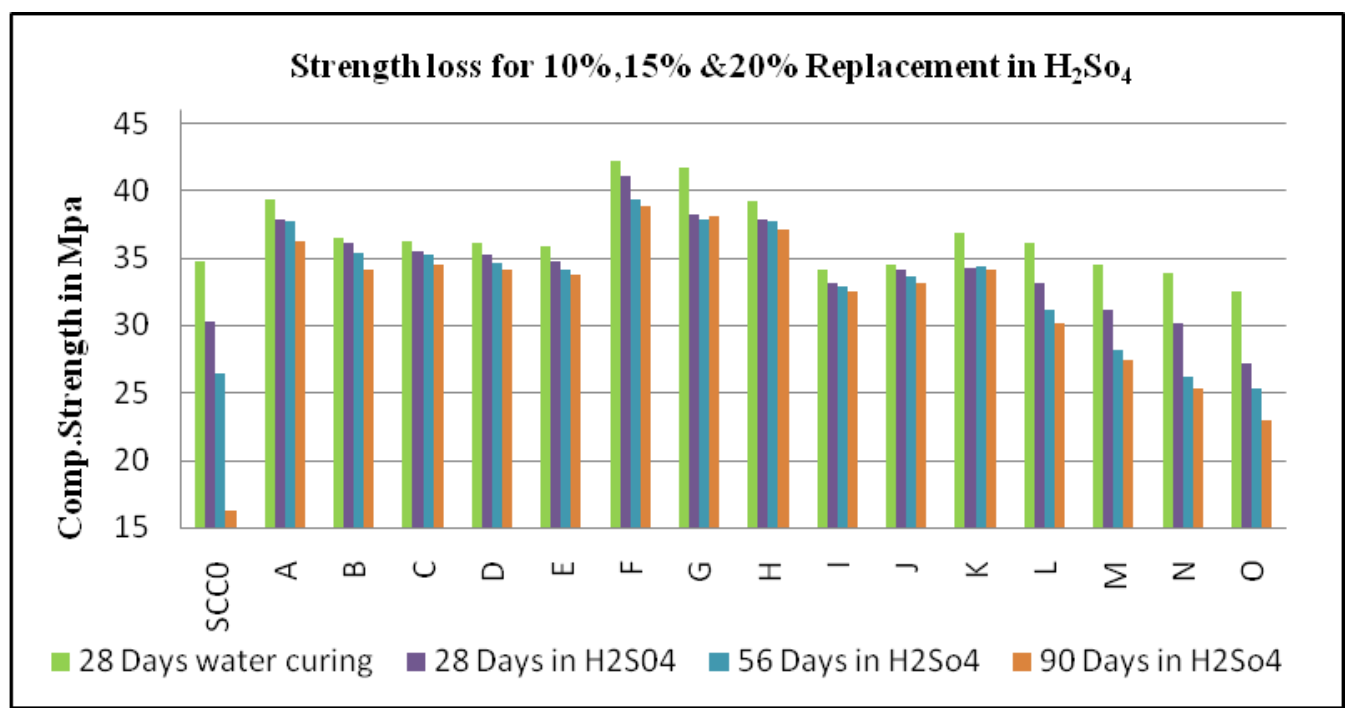

Fig.4. Test results of compressive strength loss after immersion in $\mathrm{H}_{2} \mathrm{SO}_{4}(5 \%)$ for 28,56 and 90 days
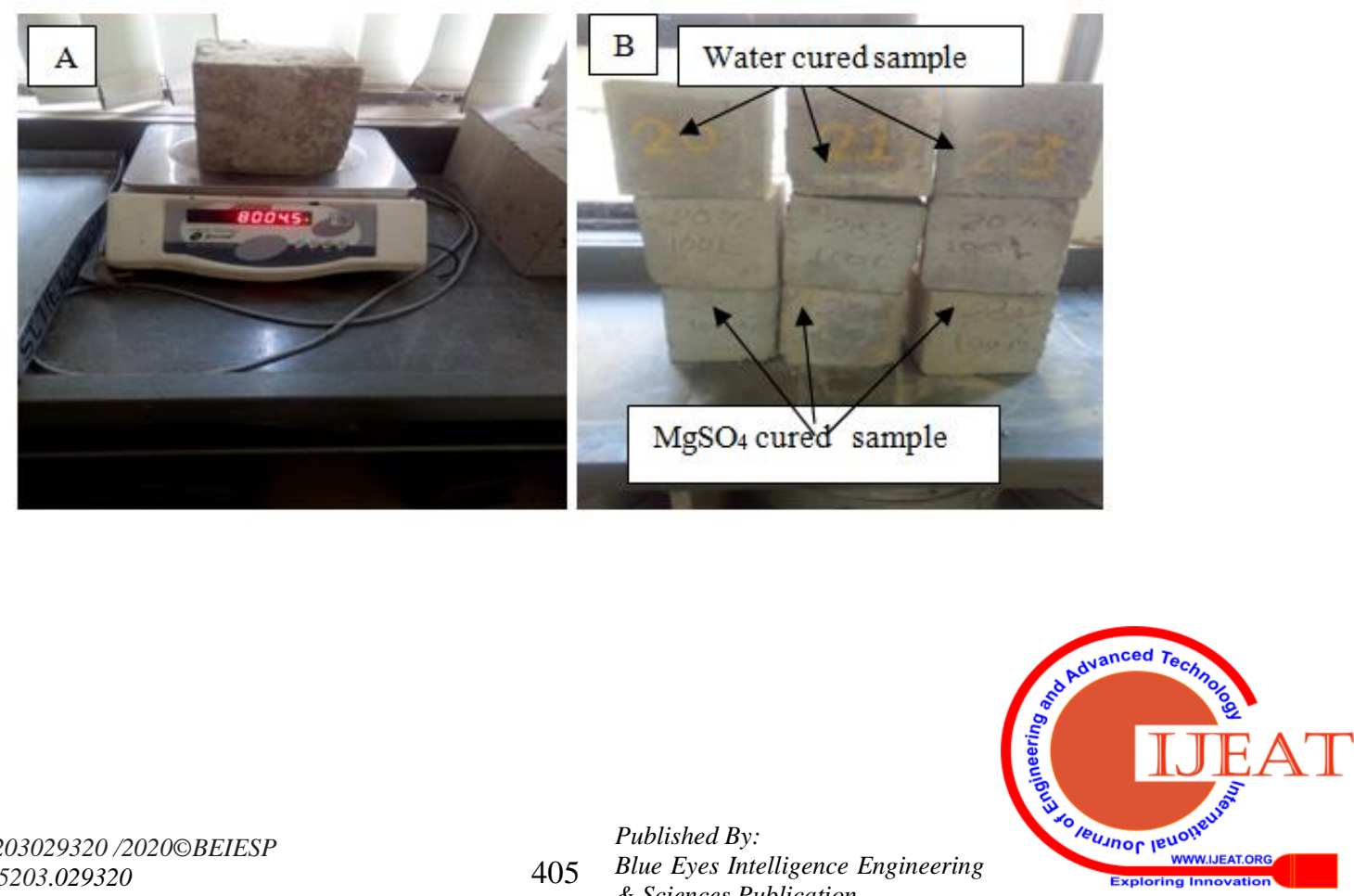

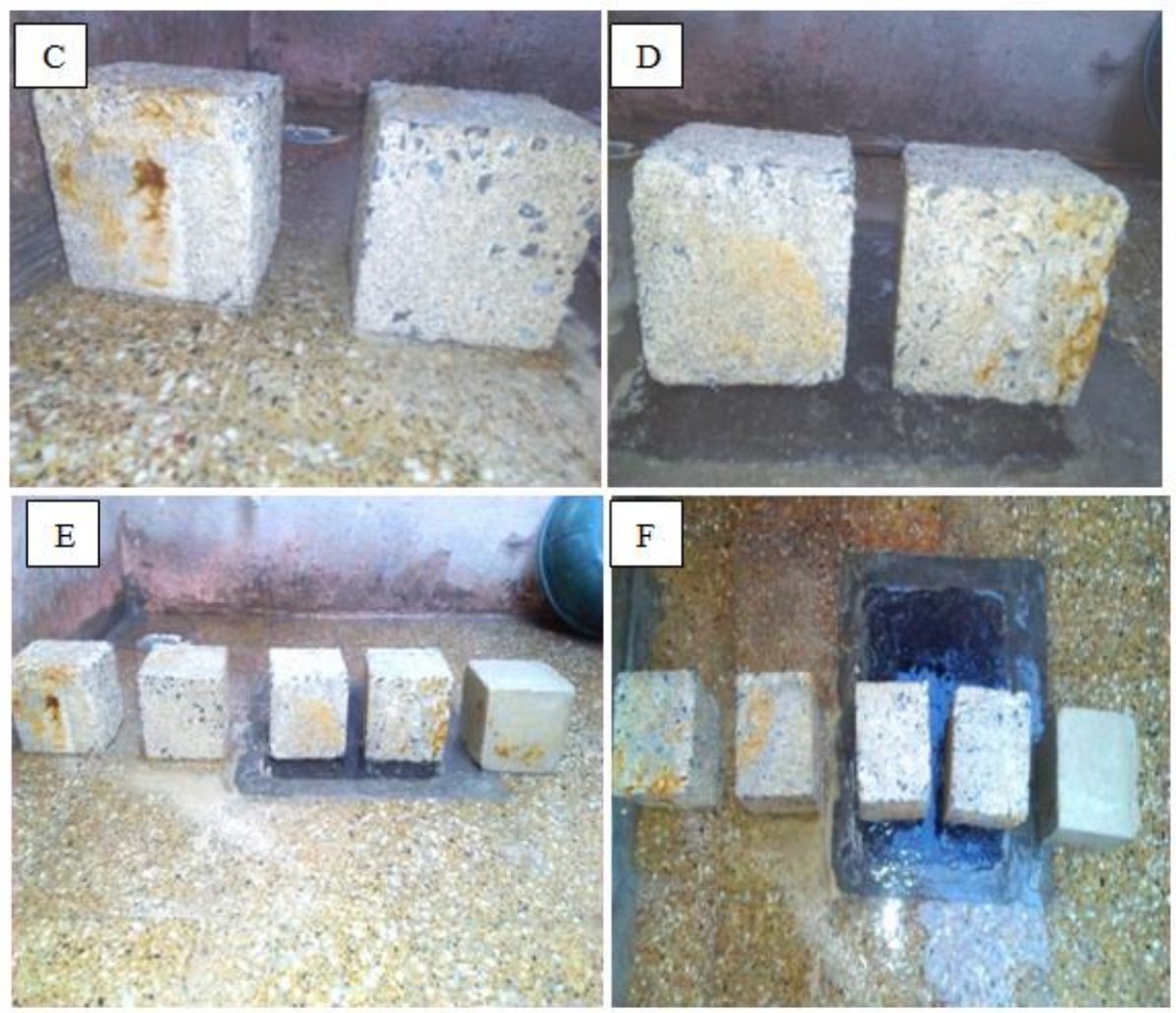

Fig. 5 Test specimen arrangement before and after Acid test [A-F]

The internal framework of a concrete member upset when sulfate ions react with the cement paste. As a result, the diversity in the material property of segments likes the decline in weight, change in diagonal dimension, and strength failure occurred. Also, that member can undergo a gradual and bottomless rearrangement of its intrinsic microstructure called physical sulfate attack [23]. The destructive element Ettringite produced when $\mathrm{C}_{3} \mathrm{~A}$ substance of a binder (cement) chemically acted with negative ion of $\mathrm{SO}^{2}{ }^{2}$, $\mathrm{Na}$, and $\mathrm{KOH}$ [22].The stability of SCC and SCC0 to sulfate attack examined by assessing the loss of compressive strength or change in compressive strength of SCC cubes dipped in sulfate water having $5 \%$ of sodium sulfate $\left(\mathrm{MgSO}_{4}\right)$ by weight of water. The sample of SCC and SCC0 cubes of $150 \mathrm{~mm}$ size after 28 days of water curing and dried for one day dipped in 5\% $\mathrm{MgSO}_{4}$ up to ninety days. After 28, 56 and 90 days of immersion period, the SCC cubes removed from the solution and clean out loose materials by a soft brush. All SCC sample tested for compressive strength following the procedure prescribed in IS: 516- 1959. Table III represents the percentage loss in strength of M30 of different mixes immersed in Sulfate solution.

\section{- Effect of $\mathrm{MgSO}_{4}$ on mass change of SCC}

The change in mass for the all blended samples of concrete exposures to sulfate up to 28, 56 and 90 days after wetted in the potable water shown in Fig. 6. After immersing $5 \%$ of MgSO4 solution, the cubes weighted and compared with initial weight before test. The difference of initial weight and final tested weight of a surface dry sample of SCC was average $0.8 \%$ (70grams).
Hence, from the two-way assessment, it recorded that no change or negligible change observed from 28 to 90 days, and this was similar to the result of the researcher [15, 24]. From all these results, the mass loss value of $1.2 \%$ (119 grams) observed in the SCC0 concrete mixture compared to other mixes at 28, 56, and 90 days. The blended specimen had sustained their integrity with very lesser distress seen on the surface when physically examined, the decline of mass for all three $(10,15$, \& $20 \%)$ with different combinations in the range of $0.8 \%$ only. The binary and ternary SCC samples gained better resistance against aggressive sulfate exposure; therefore, the mass loss can be a measure of sulfate attack due to the CaSO4 formation, the loss of mass is the most reliable sign to assess the quality of degeneration compared to changes in length and strength [25].

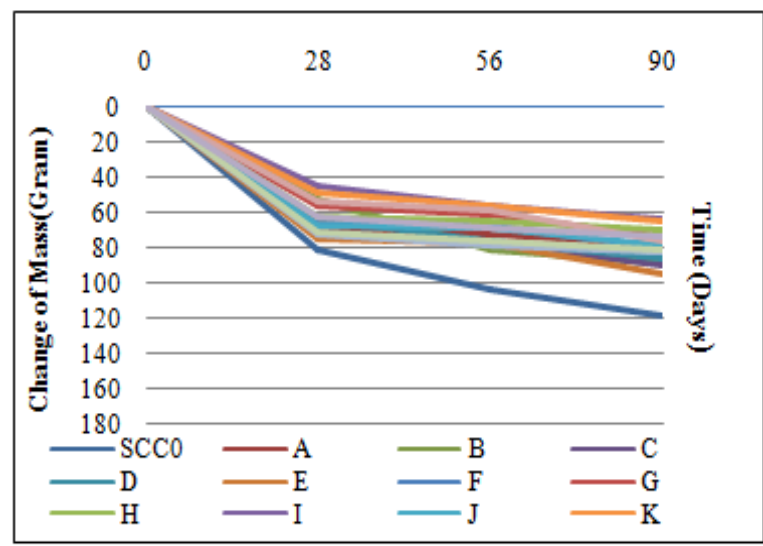

Fig-6 Effect on mass loss in MgSO4 up to 90 days

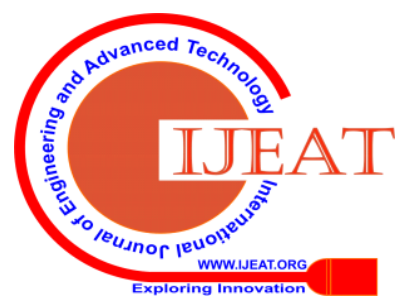




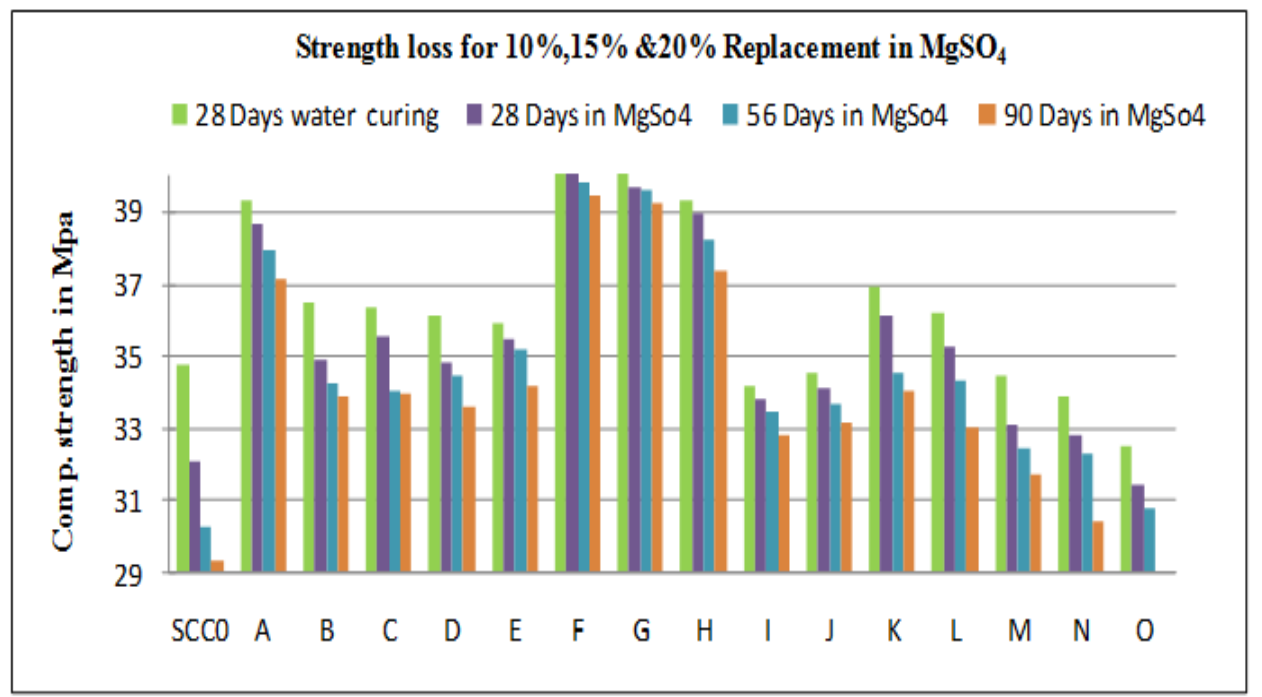

Fig-7 Effect of $\mathrm{MgSO}_{4}$ on compressive strength loss for SCC0 and blended specimen up to 90 days

The resistance of concrete to sulfate attacks studied by determining the loss of compressive strength or change in compressive strength of concrete cubes dipped in sulfate solution of $5 \%$ of Magnesium sulfate $\left(\mathrm{MgSO}_{4}\right)$ by weight of water. The sixteen SCC specimens after 28 days of water curing and dried for one day dipped in $5 \%\left(\mathrm{MgSO}_{4}\right)$ for 28,56 and 90 days. In this experimental study, the SCC samples tested for compressive strength obey the method directed in IS: 516- 1959. Table 3 represents the percentage loss in strength of M30 of different mixes due to Sulfate. The compressive strength loss after dipped in MgSO4 (base) shown in Fig. 7. The compressive strength loss after dipped in $\mathrm{MgSO}_{4}$ (base) observed 7.77\%, $12.83 \%$, and $15.65 \%$ for SCC0 specimen with immersion period 28,56, and 90 days respectively, the strength (difference) was 2 to $5 \mathrm{MPa}$. When an $\mathrm{SO}^{-2}$ reacts with paste matrix, interlink within the cement paste and aggregate skeleton as C-H-S gel cracked down. For binary and ternary mixes with different combinations of filler exhibited $3 \%$ to $7 \%$ strength losses in $10 \%, 15 \%$ of cement supplements and $7 \%$ to $12 \%$ in $20 \%$ replacement. At the age of 28, 56 and 90 days, mixes exhibited less loss in strength in the $\mathrm{MgSO}_{4}$ solution.

The effect of acidic environmental tested and performed by all binary and ternary mixes including SCCO. In an acid attack test and sulfate test, almost the same performance observed in $15 \%$ replacement cases resulted in better resistance against external chemical attack, while SCC0 specimen failed to perform in both the aggressive test. The definite impacts of different filler in SCC on hardened concrete properties have seen. The reason can be said as that the micro-fine rounded particles of two fillers LW and MW powder serves an inert supplement and packed the system of concrete by filling of voids. Hence, filler offer void less mass of SCC and provides greater defense against any chemical changes.

\section{Ultrasonic Pulse Velocity Test}

Ultrasonic frequencies are utilized in structural engineering to ascertain material properties, detect faults, and evaluate deterioration. Ultrasonic wave distribution features which will be practice for these purposes are: quickness, attenuation, wavelength, and potential. In estimating material decay, an associate-standard value, similar ultrasonic pulse velocity (UPV) selected using lab specimens; Field calculations are matched with the relating field value to judge the fitness of the material. By an electro-acoustical transducer, the ultrasonic oscillation created. The generated oscillation from a transducer caused the concrete specimen to undergo various reflections at the edges of the different material states inside the concrete. A winding system of strain waves generated, which comprises three waves namely, compression, shear, and Rayleigh waves. The most active waves (compression) collected by a transducer and identify the origin of the longitudinal waves.

For dissimilarity examination of the concrete member, the pulse speed technique feasibly helpful. The speed of generated waves is relatively self-governing of the structure of the materials within they move and based entirely on elastic characteristics. The fundamental concepts of a systematic evaluate the standard of the concrete member, the relatively higher speed of waves achieved when the microstructure quality of the concrete member is homogeneous, uniformed, and dense. In case of worse quality, lower velocities received. If the concrete specimen contained within honeycomb, cracks, voids, and defects, the waves disturbs when it passes at a discontinuity, hence, the path transmission length increases and takes more time to reach up to receiving transducer kept at other ends of the concrete member. Consequently, a lower velocity of waves detected. The real pulse velocity achieved depends principally upon the property of materials and mix design of concrete. The aggregate characteristics, filler quality, and content also remarkably influence the pulse velocity [26].

In the present experimental work, a model UP4600L used to measure the pulse transmission time as shown in Fig.8 and as per IS:13311Part-1[27]. Before starting the test, the instrument calibration carried out by calibration rod of transmission time $25.4 \mu \mathrm{s}$. The ultrasonic gel applied on the surface of a specimen and on the transducer to remove air voids between contacts. 
As per reference Table 2 of 7.11 given in IS:13311 Part-1[27], the pulse velocity received in the UPV test from 3.5 to $4.5,3.0$ to 3.5 , and below $3.0 \mathrm{~km} / \mathrm{s}$ the material quality considered, Excellent, Good and Doubtful respectively. At 28 days of water curing, a nondestructive test carried out for SCC0, binary, and ternary blended SCC specimens. After the computation, the value obtained for SCC0 for periods of 28 days was $4.42 \mathrm{Km} / \mathrm{s}$ as indicated in Table III. The value obtained, 'Good' and nearer to the 'Excellent' in the quality grading phase. While the remaining fifteen SCC mixes had resulted value lies between 3.51 to $4.94 \mathrm{Km} / \mathrm{s}$. For $10 \%$ and $15 \%$ filler mixes, the higher pulse velocity obtained, as a result, outcomes show a significant effect of two fillers of pulse velocity in SCC. A related remark presented by Aliabdo et al., and Ashish [28, 29]. The three mixes $50 \mathrm{LW}-50 \mathrm{MW}, 75 \mathrm{LW}-25 \mathrm{MW}$, and $100 \mathrm{LW}-0 \mathrm{MW}$ of $20 \%$ fillers given the irrelevant outcomes. The presence of two fillers may not increase the pulse velocity of SCC, all those values also considered a compacted and void-free (excellent and good) quality of SCC.
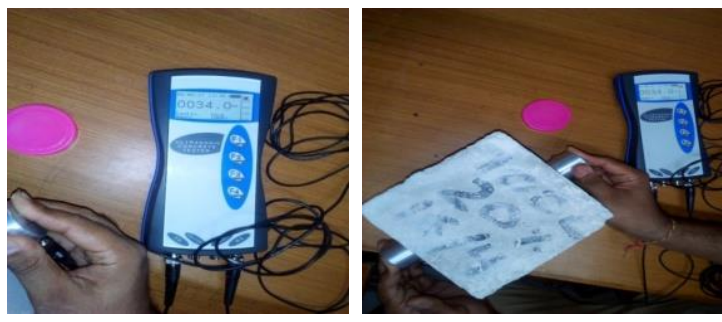

Fig.8 Ultrasonic pulse velocity test

\section{CONCLUSION}

From the outcomes of existing laboratory work of SCC mix contained LW and MW, following explanation cam be represented.

- It was remarked that the LW and MW fillers produce an active impact on the durability characteristics of blended SCC and made SCC stable and strong against acid and sulfate effect.

- The results of the weight loss and visual assessment reveal that the increase in amount of LW would enhance the performance of concrete, while inclusion of LW and MW in concretes has shown positive results in terms of resistance against sulfate attack.

- The mixtures with ternary binders of OPC, MW and LW experienced the lowest strength loss after exposure to high concentrations of sulfate attack.

- It was noted from the durability studies that in almost all cases the loss in durability is reduced in binary and ternary mixes compared to normal SCC.

- From this investigation, it is recommended that LW and MW can be utilized effectively as a filler up to $20 \%$ (Not limited to ) for casting new structural concrete, to get better workability and long term strength.

\section{REFERENCES}

1. S. Assié, G. Escadeillas, and V. Waller, "Estimates of self-compacting concrete 'potential' durability," Constr. Build. Mater., vol. 21, no. 10, pp. 1909-1917, 2007.

2. M. V. S. Reddy, Ramana Reddy, K Madan Mohan Reddy, and C M Ravi Kumar, "Durability Aspects,” vol. 2, no. 1, pp. 40-46, 2013.
3. I. B. Topçu, T. Bilir, and T. Uygunoğlu, "Effect of waste marble dust content as filler on properties of self-compacting concrete," Constr. Build. Mater., 2009.

4. P. L. Domone, "Self-compacting concrete: An analysis of 11 years of case studies," Cem. Concr. Compos., 2006.

5. V. Bonavetti, H. Donza, G. Menéndez, O. Cabrera, and E. F. Irassar, "Limestone filler cement in low w/c concrete: A rational use of energy," Cem. Concr. Res., vol. 33, no. 6, pp. 865-871, Jun. 2003.

6. A. Leemann, P. Nygaard, and P. Lura, "Impact of admixtures on the plastic shrinkage cracking of self-compacting concrete," Cem. Concr. Compos., vol. 46, pp. 1-7, 2014.

7. P. Dinakar, K. G. Babu, and M. Santhanam, "Durability properties of high volume fly ash self compacting concretes," Cem. Concr. Compos., vol. 30, no. 10, pp. 880-886, 2008.

8. IS: 12269, "Ordinary Portland Cement, 53 Grade-Specification (First Revision)," Bur. Indian Stand., no. March, 2013.

9. ASTM, "Standard Specification for Portland Cement - ASTM C-150," ASTM D-150. 2012

10. N. Su and B. Miao, "A new method for the mix design of medium strength flowing concrete with low cement content," Cem. Concr. Compos., vol. 25, no. 2, pp. 215-222, 2003.

11. S. A.- VV Karjinni, "Mixture proportion procedure for SCC," Indian Concr. journal, vol. 83, no. 6, pp. 35-41, 2009.

12. IS 383: 2016, "Coarse and fine aggregate for concrete - specification (third revision)," Indian Stand., vol. third edit, no. January, 2016.

13. ASTM, "ASTM C127 - 01 Standard Test Method for Density, Relative Density (Specific Gravity), and Absorption of Coarse Aggregate," ASTM Int., 2001.

14. H. W. Bennenk, "The European Guidelines for Self-Compacting Concrete Specification, Production and Use ii " The European Guidelines for Self Compacting Concrete " CONTENTS," 2005.

15. S. S. Vivek and G. Dhinakaran, "Durability characteristics of binary blend high strength SCC," Constr. Build. Mater., vol. 146, pp. 1-8, 2017.

16. G. C. TJR MC Nataraja, "Concrete mix design using copper slag as fine aggregate," Int. J. Civ. Eng. Technol., vol. 5, no. 9, pp. 90-99, 2014

17. ASTM International, "ASTM C 267-97, 'Standard Test Methods for Chemical Resistance of Mortars, Grouts, and Monolithic Surfacing and Polymer Concretes,' American Society for Testing and Materials (ASTM).," ASTM Int. West Conshohocken, PA, 1997.

18. IS 516, "Method of Tests for Strength of Concrete," Bur. Indian Stand. Dehli, pp. 1-30, 2018.

19. B. Y. P. K. Mehta and R. W. Burrows, "Durable_Concrete_Structmehtaci2001_178.Pdf," no. March, pp. $57-63,2001$.

20. S. Venkateswara Rao, M. V. Seshagiri Rao, D. Ramaseshu, and P. Rathish Kumar, "Durability performance of self-compacting concrete," Mag. Concr. Res., vol. 64, no. 11, pp. 1005-1013, 2012.

21. M. Collepardi, "A state-of-the-art review on delayed ettringite attack on concrete," Cem. Concr. Compos., vol. 25, no. 4-5 SPEC, pp. 401-407, 2003.

22. A. Neville, "The confused world of sulfate attack on concrete," Cem. Concr. Res., vol. 34, no. 8, pp. 1275-1296, 2004.

23. J. Marchand, E. Samson, Y. Maltais, and R. J. Lee, "Predicting the performance of concrete structures exposed to chemically aggressive environments - Field validation," Proceedings, Annu. Conf. - Can. Soc. Civ. Eng., vol. 2002, no. December, pp. 1243-1254, 2002.

24. R. Dhiyaneshwaran, S., Ramanathan, P., Baskar, I., \& Venkatasubramani, "Dhiyaneshwaran, S., Ramanathan, P., Baskar, I., \& Venkatasubramani, R. (2013). Study on durability characteristics of self-compacting concrete with fly ash.," Jordan J. Civ. Eng., vol. 159, no. 3164, pp. 1-12., 2013.

25. E. H. Polivka, M., \& Brown, "Influence of various factors on sulfate resistance of concretes containing pozzolan.," Proc., pp. 1077-1100, 1958.

26. V. Patel and N. Shah, "Durability study of M70 grade structural concrete," Iran. J. Sci. Technol. - Trans. Civ. Eng., vol. 41, no. 2, pp. 241-248, 2017.

27. IS 13311 (Part 1)-1992, "Non-Destructive Testing of Concrete Methods of Test," Bur. Indian Satandards, pp. 1-7, 1992

28. A. A. Aliabdo, A. E. M. Abd Elmoaty, and E. M. Auda, "Re-use of waste marble dust in the production of cement and concrete," Constr. Build. Mater., vol. 50, pp. 28-41, 2014. 
29. D. K. Ashish, "Concrete made with waste marble powder and supplementary cementitious material for sustainable development," $J$. Clean. Prod., vol. 211, pp. 716-729, 2019.

\section{AUTHORS PROFILE}

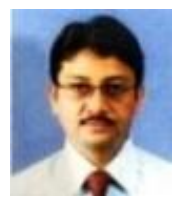

Panchal Vinod.C is Research scholar in Department of Civil Engineering, Sardar Vallabhbhai National institute of Technology (SVNIT), Surat, Gujarat, India. His area of interest is Self Compacting Concrete.

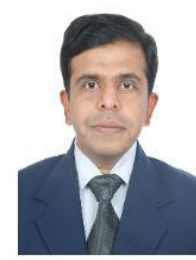

Dr.Gaurang. R. Vesmawala is working as Associate Professor in Department of Civil Engineering, Sardar Vallabhbhai National Institute of Technology (SVNIT), Surat, Gujarat, India.

His area of interest is Earthquake engineering, Structural Health monitoring, Optimum design of Space Structure and Neural network application in Structural Engineering. 